\title{
The study of the properties of $\mathrm{Hg}_{0.6} \mathrm{Tl}_{0.4} \mathrm{Ba}_{2} \mathrm{Ca}_{2}\left(\mathrm{Cu}_{1-\mathrm{x}} \mathrm{Ag}_{\mathrm{x}}\right)_{3} \mathrm{O}_{8+\delta}$ compound
}

\author{
Kareem A. Jasim ${ }^{1}$, Raghad S. Al-Khafaji ${ }^{2 *}$ \\ 1, 2 Department of Physics, University of Baghdad, Baghdad, Iraq
}

\author{
Index Terms \\ Superconductivity \\ Electrical Resistivity \\ Lattice Parameters \\ Transition Temperature \\ Dielectric Properties \\ Received: 8 June 2016 \\ Accepted: 10 July 2016 \\ Published: 12 February 2017
}

\begin{abstract}
The main aim of this research is to study the effect of silver as substitution to superconductivity behav ior of $\mathrm{Hg}_{0.6} \mathrm{Tl}_{0.4} \mathrm{Ba}_{2} \mathrm{Ca}_{2}\left(\mathrm{Cu}_{1-\mathrm{x}} \mathrm{Ag}_{\mathrm{x}}\right)_{3} \mathrm{O}_{8+\delta}$ compound through modifying phase and lattice parameters, transition temper ature Tc, likewise, the dielectric properties. Bulk polycrystalline $\mathrm{Hg}_{0.6} \mathrm{Tl}_{0.4} \mathrm{Ba}_{2} \mathrm{Ca}_{2}\left(\mathrm{Cu}_{1-\mathrm{x}} \mathrm{Ag}_{\mathrm{x}}\right)_{3} \mathrm{O}_{8+\delta}$ compound compound samples with $\mathrm{x}=0.0,0.1,0.2,0.3,0.4,0.5,0.6$ and 0.7 , are synthesized by solid state reaction process. Study identifies Silver substitution on superconductivity behavior. Structural specifications are deliberated by using X-ray powder pattern, the high temperature phase superconductor (Hg-1223) of the tetragonal structure didn't change with the partial replacement of $\mathrm{Cu}+2$ by $\mathrm{Ag}+1$ ions, lattice parameters a, c ,c/a are established to vary as function of Ag- substitution. Transition temperature $\left(\mathrm{T}_{c}\right)$ has been calculated using technique of four-probe to measure electrical resistivity. Transition temperature at zero resistivity $\mathrm{T}_{c}$ (off set) decreases from 117 to $86 \mathrm{~K}$ with increasing Ag. In addition, dielectric properties (dielectric constant and loss) are characterized directly by relating with Ag concentration.
\end{abstract}

\section{INTRODUCTION}

A superconducting system of $\mathrm{Hg}-\mathrm{Ba}-\mathrm{Ca}-\mathrm{Cu}-\mathrm{O}$ family has been exposed, with even higher critical temperature. Recently the high Tc superconductor $\mathrm{Hg}_{0.6} \mathrm{Tl}_{0.4} \mathrm{Ba}_{2} \mathrm{Ca}_{2}\left(\mathrm{Cu}_{1-\mathrm{x}} \mathrm{Ag}_{\mathrm{x}}\right)_{3} \mathrm{O}_{8+\delta}$ which is $\mathrm{Hg}$-based, has enticed much responsiveness due to the highest superconducting transition temperature $\left(\mathrm{T}_{-} c\right) \sim 135 \mathrm{~K}$ at ambient conditions, and moderate flux pinning strength at temperature up to $77 \mathrm{~K}$ [1-3]. However, the high vapor pressure causes the production of these materials at ambient pressure to be stimulated, high vapor pressure of $\mathrm{Hg}$ at synthesis temperature $\sim$ (700-850 0C), formation of $\mathrm{C}_{a} \mathrm{H}_{g} \mathrm{O}_{2}$ insulating phase at $500 \mathrm{OC}$ and $\mathrm{CO}_{2}$ and $\mathrm{H}_{2} \mathrm{O}$ as contamination which is presented in the atmosphere [4].

Moreover, the synthesizing phases are oxygen scarce leading to under doped materials. That causes the manufactured Hg-12(n-1) n phases to be unstable like the other high transition temperature superconductor phases (HTSC) of cuprate oxide group. To overcome these problems, many attempts have been proposed but they have only limited accomplishments [5-7]. The considerable difficulty was experienced in the synthesis of Hg bearing HTSC phases including Hg-1223 because of their extreme sensitivity towards contamination from humidity and carbon dioxide. The Hg-1223 samples are known to degrade rapidly after synthesis.

In view of the improvement of the stability of the Hg manner HTSC phases, concerning the Hg-1223 phase, significant efforts have been employed recently. The most effective method that is known now to develop the constancy of the Hg-1223 phase is that through choosing suitable cationic substitution for Hg. Typically, cations that have oxidation states higher than that of $\mathrm{Hg}^{+2}$ and bigger than +2 are suited cations. Oxygen deficient indemnification $\mathrm{H}_{g}-O_{\delta}$ layer leads to phase stability. The cations of higher oxidation state also conduct the hole optimization in the hole lacking as grown Hg-1223 phase, thus, critical transition temperature must produce the optimum. A diversity

\footnotetext{
*Corresponding author: Raghad S. Al-Khafaji

${ }^{\dagger}$ Email: raghadsubhiabbas@yahoo.com
} 
of cationic substitution such as, $\mathrm{Tl}^{+3}, \mathrm{Bi}^{+3}, \mathrm{Re}{ }^{+4}, \mathrm{~Pb}^{+4}$, $\mathrm{Sb}^{+3,5}$ and $\mathrm{Cu}^{+2}$ has been made an effort [8-13]. Nevertheless, the cationic size is another important doping cationic parameter, but it has not been studied in detail yet. Likely, some important characteristics will be influenced through size of doping cation. The size of the doping ions will be dependent on Tc since incongruity of doping ions sizes with native $\mathrm{Hg}$ ions will create local pressure.

Also, the substitution of cation with different sizes will be modified by band overlap, and which may also lead to change in critical transition temperature [14, 25, 26]. The degree of stability and microstructure through the strain is produced in the $\mathrm{HgO}$ layer and which will be influenced by the cationic size is considered another characteristic. Viewing what has been said above, Hg-1223 has been substituted with $\mathrm{T} 1$ which is taken in variable concentrations stability of Hg-1223 phase and the $\mathrm{Hg}_{1-X}$ $\mathrm{Tl}_{X} \mathrm{Ba}_{2} \mathrm{Ca}_{2} \mathrm{Cu}_{3} \mathrm{O}_{8+\delta}$ Superconductors have been investigated. It can be useful to mention that $\mathrm{Tl}$ has been individually formed and employed successfully for the Hg-1223 substitution. It has been found that with un-doped Hg-1223 for $\mathrm{Hg}_{0.80} \mathrm{Tl}_{0.20} \mathrm{Ba}_{2} \mathrm{Ca}_{2} \mathrm{Cu}_{308} \mathrm{O}_{8.293}$, the maximum $\mathrm{Tc}$ (onset) of $136 \mathrm{~K}$ is obtained [15].

Using flow rate of oxygen higher than $0.25 \mathrm{~L} / \mathrm{min}$ produces deformed samples, oxygen stoichiometric of Hg-based superconductors with $\delta=0$ are unstable [16], although the structure can be stabilized by inserting further oxygen, which, in turn, creates more holes in the $\mathrm{CuO}_{2}$ layers. The holes concentration increasing in the high-Tc phase will enhance the Tc(off) and Tc(onset)[17]. In this paper, the synthesis and characterization of $\mathrm{Hg}_{0.6} \mathrm{Tl}_{0.4} \mathrm{Ba}_{2} \mathrm{Ca}_{2}\left(\mathrm{Cu}_{1-\mathrm{x}} \mathrm{Ag}_{\mathrm{x}}\right)_{3} \mathrm{O}_{8+\delta}$ Bulk polycrystalline superconductor has been described with concentrations range of (0-0.7) with increment 0.1 by using three steps solid state reaction procedure. $\mathrm{Hg}_{0.5} \mathrm{~Pb}_{0.5} \mathrm{Ba}_{2} \mathrm{Ca}_{2} \mathrm{Cu}_{3} \mathrm{O}_{8+\delta}$ have been substituted with $\mathrm{Ag}$ taken in a variety of concentrations stability of Hg-1223 phase. The transverse resistivity of these samples is measured at different temperatures ranging between onset temperature and zero resistance temperature. The main aim of this research is to study the effect of silver as substitution to superconductivity behavior of $\mathrm{Hg}_{0.6} \mathrm{Tl}_{0.4} \mathrm{Ba}_{2} \mathrm{Ca}_{2}\left(\mathrm{Cu}_{1-\mathrm{x}} \mathrm{Ag}_{\mathrm{x}}\right)_{3} \mathrm{O}_{8+\delta}$ compound through modifying phase and lattice parameters, transition temperature Tc, likewise, the dielectric properties.

\section{EXPERIMENTAL TECHNIQUE}

By utilizing three steps of solid state technique, Polycrystalline samples of type $\mathrm{Hg}_{0.6} \mathrm{Tl}_{0.4} \mathrm{Ba}_{2} \mathrm{Ca}_{2}\left(\mathrm{Cu}_{1-\mathrm{x}} \mathrm{Ag}_{\mathrm{x}}\right)_{3} \mathrm{O}_{8+\delta}$ ISSN: 2414-3103

DOI: $10.20474 /$ japs-3.1.4 are prepared with $\mathrm{x}=0.0,0.1,0.2,0.3,0.4,0.5,0.6$ and 0.7 . The amount of high purity powder is appropriate, $\mathrm{Tl}_{2} \mathrm{O}_{3}$, $\mathrm{BaO}_{2}, \mathrm{CaO}, \mathrm{HgO}, \mathrm{CuO}$ and, in the correct stoichiometric pro-

portions, Ag-metal has been weighed and grounded in an agate mortar. The preparation method has been described in [18]. The samples are characterized by X-ray diffract meter. Conventional four-probe technique is applied for electric resistivity measurements of the prepared samples in a temperature from 300 down to $77 \mathrm{~K}$. As well as, the excess of oxygen content $(\delta)$, critical temperatures Tc and volume fraction for the phase (Vphase) have been calculated. Lattice parameters a and c have been calculated via computer program which is based on the method of Cohen,s least square $[19,20]$. LCR meter (Hewlett-Packard, USA)- HP-R2C unit $4274 \mathrm{~A}$ in the range $(100 \mathrm{kHz}-10 \mathrm{MHz})$ and the Agilent 4275B LCR meter of (Agilent Technologies Japan, Ltd.) in the range (1 kHz-100 kHz) are employed for dielectric measurements. To both surfaces of the specimen, silver electrode can be applied, and copper leads are fixed. The capacitance (C) and $(\tan \delta)$ were recorded, then dielectric constant $(\varepsilon)$ and loss $\left(\varepsilon^{\prime}\right)$ have been calculated by using the following expressions [21]:

$$
\begin{gathered}
\varepsilon^{\prime}=\frac{C t}{A \varepsilon \theta^{\prime \prime}} \\
\tan \delta=\frac{\varepsilon^{\prime}}{\varepsilon^{\prime}}
\end{gathered}
$$

Where

$\mathrm{t}$ : the thickness of the pellet $(0.2 \mathrm{~cm})$

$\varepsilon_{o}$ : the permittivity of space $(8.85 * 10-12 \mathrm{~F} / \mathrm{m})$

A: the effective cross area of the applied electrode.

Dielectric measurements of frequency dependent for compounds $\mathrm{Hg}_{0.6} \mathrm{Tl}_{0.4} \mathrm{Ba}_{2} \mathrm{Ca}_{2}\left(\mathrm{Cu}_{1-\mathrm{x}} \mathrm{Ag}_{\mathrm{x}}\right)_{3} \mathrm{O}_{8+\delta}$ (doped with $\mathrm{x}=$ $0.0,0.1,0.2,0.3,0.4,0.5,0.6$ and 0.7$)$ are done at the room temperature .

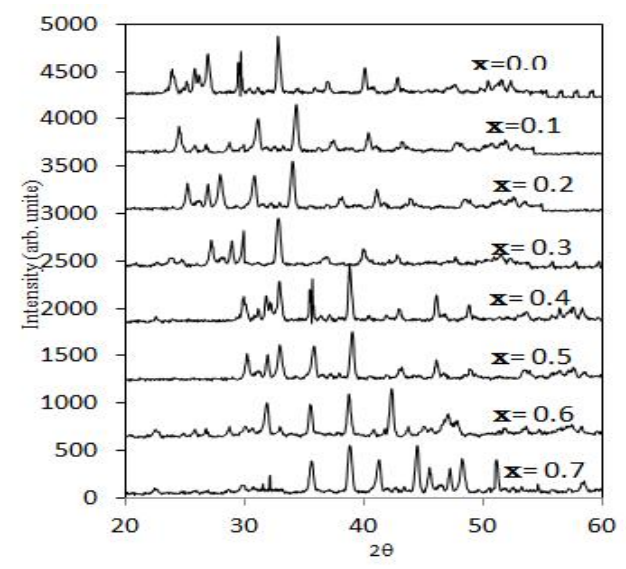

Fig. 1. XRD patterns for $\mathrm{Hg}_{0.6} \mathrm{Tl}_{0.4} \mathrm{Ba}_{2} \mathrm{Ca}_{2}\left(\mathrm{Cu}_{1-\mathrm{x}} \mathrm{Ag}_{\mathrm{x}}\right)_{3} \mathrm{O}_{8+\delta}$ compound with $\mathrm{x}=0.0,0.1,0.2,0.3,0.4,0.5,0.6$ and 0.7

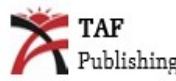




\section{RESULTS AND DISCUSSION}

Fig 1 shows series XRD patterns for $\mathrm{Hg}_{0.6} \mathrm{Tl}_{0.4} \mathrm{Ba}_{2} \mathrm{Ca}_{2}$ $\left(\mathrm{Cu}_{1-\mathrm{x}} \mathrm{Ag}_{\mathrm{x}}\right)_{3} \mathrm{O}_{8+\delta}$ compound $\mathrm{x}=0.0,0.1,0.2,0.3,0.4,0.5$, 0.6 and 0.7) compounds. The figure observes high transition temperature phase (Hg-1223 phase) with a small amount of the second phase Hg-1212 (low phase) for $\mathrm{HgBa}_{2} \mathrm{Ca} 1\left(\mathrm{Cu}_{1-\mathrm{x}} \mathrm{Ag}_{x}\right)_{2} \mathrm{O}_{6+\delta}$ and 1201 for other composites that have been composed of synthesized samples. Furthermore, it is significant to notice that no other mark of an impurities phase is present that shows the peritectic reaction is completed for all samples. It can be clearly seen from table 1 that with increasing Ag content, the lattice parameters ( $\mathrm{a}$ and $\mathrm{c}$ ), the transition temperature Tc is shown decreasing.

TABLE 1

VALUES OF TEMPERATURE TRANSITION (TC(OFFSET),TC(ONSET)), THE EXCESS OF OXYGEN CONTENT( $\triangle$ ), LATTICE PARAMETERS(A, $\mathrm{C}$,AND C/A), FOR ALL SAMPLES AT VARIOUS COMPOSITIONS OF $\mathrm{Hg}_{0.6} \mathrm{Tl}_{0.4} \mathrm{Ba}_{2} \mathrm{Ca}_{2}\left(\mathrm{Cu}_{1-\mathrm{x}} \mathrm{Ag}_{\mathrm{x}}\right)_{3} \mathrm{O}_{8+\delta}$

\begin{tabular}{lllllll}
\hline \hline $\mathrm{X}$ & $\mathrm{Tc}$ (Offset) $(\mathrm{K})$ & $\mathrm{Tc}$ (Onset) $(\mathrm{K})$ & $\delta\left(\mathrm{o}_{2}\right)$ & $\mathrm{a}(\mathrm{A} 0)$ & $\mathrm{c}(\mathrm{A0})$ & $\mathrm{c} / \mathrm{a}$ \\
\hline 0.0 & 117 & 134 & 0.203 & 3.842 & 15.81 & 4.115 \\
0.1 & 110 & 127 & 0.192 & 3.839 & 15.78 & 4.110 \\
0.2 & 106 & 122 & 0.163 & 3.836 & 15.76 & 4.108 \\
0.3 & 97 & 119 & 0.136 & 3.833 & 15.75 & 4.109 \\
0.4 & 93 & 111 & 0.113 & 3.832 & 15.73 & 4.104 \\
0.5 & 86 & 102 & 0.070 & 3.831 & 15.72 & 4.103 \\
0.6 & --- & --- & 0.011 & 3.830 & 15.64 & 4.083 \\
0.7 & --- & --- & 0.003 & 3.831 & 15.58 & 4.066 \\
\hline \hline
\end{tabular}

Depression in Tc for Ag combined is caused by the formation of a non-superconducting phase and the defects which are made by Ag clusters [21]. The results of resistivity as a function of temperature for compound $\mathrm{Hg}_{0.6} \mathrm{Tl}_{0.4} \mathrm{Ba}_{2} \mathrm{Ca}_{2}\left(\mathrm{Cu}_{1-\mathrm{x}} \mathrm{Ag}_{\mathrm{x}}\right)_{3} \mathrm{O}_{8+\delta}$ with $\mathrm{x}=0.0,0.1,0.2,0.3$, $0.4,0.5,0.6$ and 0.7 are displayed in fig.2. With increasing A concentration the regular state resistivity modification from metal to semiconductor behavior takes place. As the Ag weight fractions increase with $\mathrm{x}=0.0,0.1,0.2,0.3,0.4$ and 0.5 , at high temperature, the obtained samples show a metallic behavior, followed by a superconductivity transition with offset transition temperature at zero resistance $\operatorname{Tc}$ (offset) $=117,110,106,97,93$ and $86 \mathrm{~K}$ and the onset transition temperature $\mathrm{Tc}$ (onset) $=134,127,122,119,111$ and $102 \mathrm{k}$ respectively.

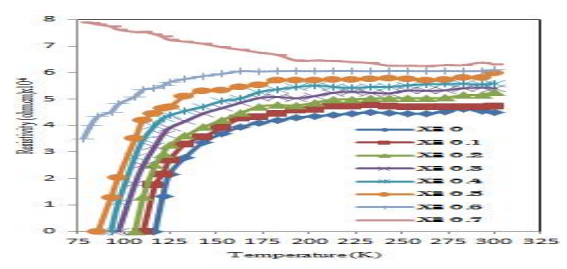

Fig. 2. The resistivity vs temperature for

$\mathrm{Hg}_{0.6} \mathrm{Tl}_{0.4} \mathrm{Ba}_{2} \mathrm{Ca}_{2}\left(\mathrm{Cu}_{1-\mathrm{x}} \mathrm{Ag}_{\mathrm{x}}\right)_{3} \mathrm{O}_{8+\delta}$ samples $(\mathrm{x}=0.0,0.1,0.2$, $0.3,0.4,0.5,0.6$ and 0.7 )

ISSN: $2414-3103$

DOI: $10.20474 /$ japs-3.1.4
It has been revealed from fig. 2 the transition of superconducting is truant for the sample with $\mathrm{x}=0.6$, but electrical resistivity, in high temperature region, displays a metal behavior. Concerning the sample with $x=0.7$, the resistivity behavior is similar to semiconductors at room temperature (RT) down to $77 \mathrm{~K}$. Anderson impurity model [22] has explained the behavior above.

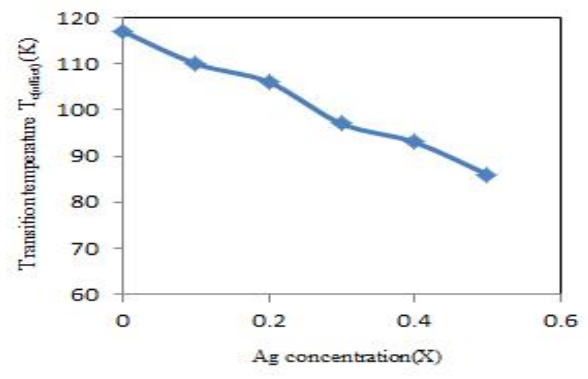

Fig. 3. The transition temperature Tc(offset) vs Ag content from 0 to 0.5 )

Electronic state is traveling near the Fermisurface for large overlap between the $\mathrm{Cu}(3 \mathrm{~d})$ and $\mathrm{O}(2 \mathrm{p})$, wave which functions for the high doping level state. While becomes localized when this overlap is lessened. Some modifications of microstructure and chemical properties 
of $\mathrm{CuO}_{2}$ planes result in the replacement of $\mathrm{Cu}^{2+}$ ions by $\mathrm{Ag}^{1+}$ ions. The oxidation state of copper in $\mathrm{CuO}_{2}$ planes might have been altered due to this replacing (from lower oxidation state cations), conducting a lower concentration and transition temperature carrier. Besides, the influence of coper-pair breaking of magnetic ions is being aware of depressing the temperature of transition through the short and scattering range change. Fig. 3 shows the transition temperature $\mathrm{Tc}$ (offset) as a function of $\mathrm{Ag}$ content from 0.0 to 0.5. It is found that, with increasing of Ag contents, the transition temperature $\mathrm{Tc}$ (offset) will decrease. The obtained results can be explained that the addition of $\mathrm{Ag}$ in $\mathrm{Cu}$ site is absolutely active in decomposing the high-Tc phase (1223) of Hg-Ba-Ca-Cu-O superconductor systems by producing $\mathrm{BaHgO}_{3}$ and $\mathrm{BaCu}(\mathrm{Ag}) \mathrm{O}_{2}$ together with low-Tc phase formation [23].

The variations in the real part $(\dot{\varepsilon})$ and the imaginary part $\left(\varepsilon^{\prime}\right)$ of dielectric constant $\mathrm{Hg}_{0.6} \mathrm{Tl}_{0.4} \mathrm{Ba}_{2} \mathrm{Ca}_{2}\left(\mathrm{Cu}_{1-\mathrm{x}} \mathrm{Ag}_{\mathrm{x}}\right)_{3} \mathrm{O}_{8+\delta}$ samples $(\mathrm{x}=0.0,0.1,0.2$, $0.3,0.4,0.5,0.6$ and 0.7 ) at room temperature, as a function of frequency are shown in table 2.

TABLE 2

VALUES OF DENSITY, VOLUME FRACTION AND DIELECTRIC PROPERTIES ('EANDE') AT DIFFERENT COMPOSITIONS OF

\begin{tabular}{lllllll}
\multicolumn{5}{c}{$\mathrm{Hg}_{0.6} \mathrm{Tl}_{0.4} \mathrm{Ba}_{2} \mathrm{Ca}_{2}\left(\mathrm{Cu}_{1-\mathrm{x}} \mathrm{Ag}_{\mathrm{x}}\right)_{3} \mathrm{O}_{8+\delta}$} \\
\hline \hline $\mathrm{X}$ & $\rho \mathrm{M}(\mathrm{g} / \mathrm{cm} 3)$ & $\mathrm{VPh}-1223$ & $\mathrm{VPh}-1212$ & $\mathrm{VPh}-1201$ & $\varepsilon^{\prime}($ at 1MHz) & $\varepsilon^{\prime \prime}($ at 1MHz) \\
\hline 0.0 & 5.694 & 89.47 & 8.17 & 2.36 & 1.654 & 0.078 \\
0.1 & 5.686 & 81.16 & 15.62 & 3.22 & 1.993 & 0.109 \\
0.2 & 5.672 & 78.95 & 16.14 & 4.91 & 2.205 & 0.114 \\
0.3 & 5.661 & 76.8 & 17.94 & 6.74 & 2.522 & 0.132 \\
0.4 & 5.64 & 71.73 & 21.12 & 7.15 & 2.651 & 0.154 \\
0.5 & 5.612 & 63.53 & 27.11 & 9.36 & 2.875 & 0.167 \\
0.6 & 5.607 & 56.8 & 29.17 & 14.03 & 2.972 & 0.187 \\
0.7 & 5.601 & 48.73 & 29.23 & 22.04 & 3.119 & 0.191 \\
\hline \hline
\end{tabular}

It is clearly observed an increase in dielectric con$\operatorname{stant}\left(\varepsilon^{\prime}\right)$ and loss $\left(\varepsilon^{\prime}\right)$ at $1 \mathrm{MHZ}$ with increasing Ag concentration. On the other hand, the values of density decrease with concentration of Ag as shown in table 2, due tothe Atomic radius of $\mathrm{Ag}$ which is substituted with Cu larger than it [24].

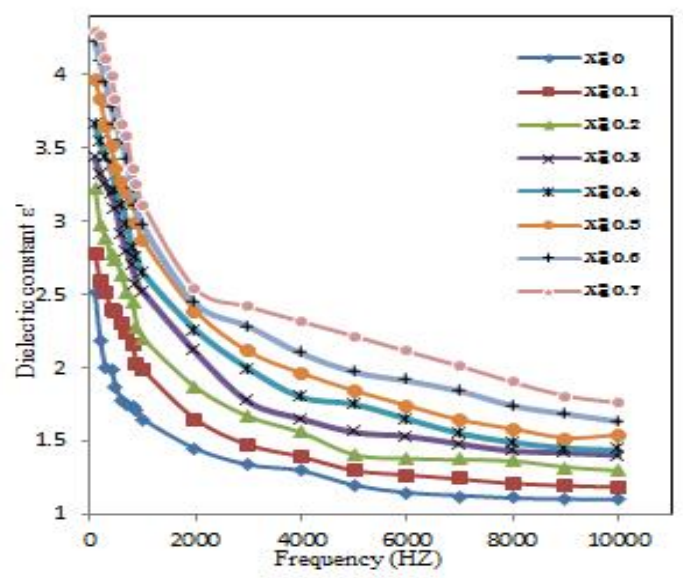

Fig. 4. Variations of dielectric constant versus frequency for

$\mathrm{Hg}_{0.6} \mathrm{Tl}_{0.4} \mathrm{Ba}_{2} \mathrm{Ca}_{2}\left(\mathrm{Cu}_{1-\mathrm{x}} \mathrm{Ag}_{\mathrm{x}}\right)_{3} \mathrm{O}_{8+\delta}$ samples $(\mathrm{x}=0,0.1,0.2$, $0.3,0.4,0.5,0.6$ and 0.7 ) at room temperature)

ISSN: $2414-3103$

DOI: $10.20474 /$ japs-3.1.4

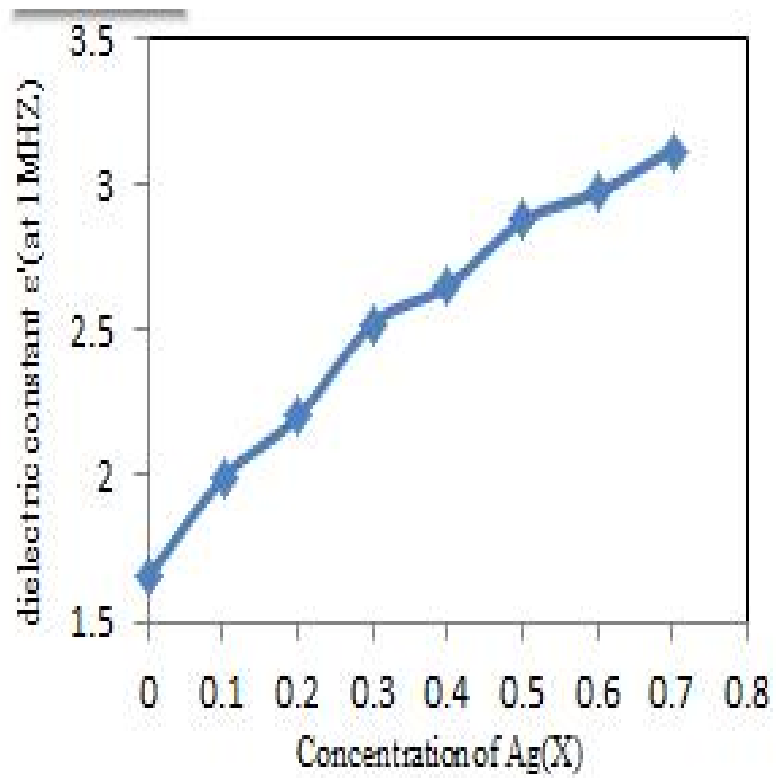

Fig. 5. Variations of dielectric constant (at 1MHZ) versus concentration ofHg ${ }_{0.6} \mathrm{Tl}_{0.4} \mathrm{Ba}_{2} \mathrm{Ca}_{2}\left(\mathrm{Cu}_{1-\mathrm{x}} \mathrm{Ag}_{\mathrm{x}}\right)_{3} \mathrm{O}_{8+\delta}$

Fig. 4 shows that the dielectric constant ( $\varepsilon$ ) decreases with increasing frequency at room temperature 
with the effect of Ag doping. Fig. 5 shows that at $1 \mathrm{MHZ}$ the dielectric constant $(\dot{\varepsilon})$ is a function of Ag concentration, it clarifies that the dielectric constant increases with increasing Ag concentration. The real part of the dielectric constant $(\varepsilon)$ awards the magnitude of the part of energy when the material is exposed to the electrical field, the energy which is stored within the material. Grains (inter-granular sites) which act like termination ends for the crystal, are the most likely places at which this energy can be stored. At applied external electric field the dielectric constant of imaginary part ( $\left.\varepsilon^{\prime}\right)$ expresses, across the interfaces, the absorption and the attenuation of energy (densities of localized charge at the sites of defect, localized defects and grain boundaries) [20-23-24].

\section{CONCLUSION}

It has been synthesized successfully i.e., $\mathrm{Hg} \quad{ }_{0.6} \mathrm{Tl}$ ${ }_{0.4} \mathrm{Ba}_{2} 2 \mathrm{Ca}_{02}\left(\mathrm{Cu}_{01-\mathrm{x}} \mathrm{Ag}_{0 \mathrm{x}}\right)_{03} \mathrm{O}_{8+\delta}$ samples utilizing solid state reaction technique with concentration range (0-0.7). XRD patterns show a tetragonal structure for all specimens. The silver substitution does not change the tetragonal structure of $\mathrm{Hg}(\mathrm{T} 1)-1223$ phase, but the parameters of lattice "a" and " $c$ " are reduced. As the silver incorporation is increased, the content of high phase and the critical transition temperatures are decreased. Moreover, the transformation behavior is shifted from superconducting to semiconducting. In addition, the dielectric properties are directly increasing with Ag contents.

\section{REFERENCES}

[1] O. Chmaissem, P. Guptasarma, U. Welp, D. G. Hinks and J. D. Jorgensen, "Effect of Re substitution on the defect structure, $\quad$ and superconducting properties of (Hg 1-x Re x) Ba 2 Ca n-1 Cu n O 2n+ 2+ $\delta(\mathrm{n}=2,3,4)$," Physica C, vol. 292, no. $\quad 305$, pp. 305-314. 1997. DOI: 10.1016/S0921-4534(97)01746-2

[2] A. Schilling, M. Cautoni, J. D. Guo and H. R. Ott, "Superconductivity above $130 \mathrm{~K}$ in the Hg-Ba-Ca-Cu-O system," Nature, vol. 363, no. 56, 1993. DOI: 10.1038/363056a0

[3] H. Richter, I. Puica, W. Lang, M. Peruzzi, J. H. Durrell, H. Sturm, ... and D. Bäuerle, "Angle dependence of the Hall effect in $\mathrm{HgBa}_{2} \mathrm{CaCu}_{02} \mathrm{O}_{0.6}$ thin films," Physical Review B, vol. 73, no. 18, pp. 184506. DOI: 10.1103/PhysRevB.73.184506

[4] R. L. Meng, B. R. Hickey, Y. Y. Sun, Y. Cao, C. Kinalidis, J. K. Meen, Y. Y. Xue and C. W. Chu, "Study of intermetallic com- $\quad$ pounds isostructural to MgB 2," IEEE Transactions on Applied Superconductivity, vol. 13, no. 2, pp. 3042-3046, 1996. DOI: $10.1109 /$ TASC.2003.812071

[5] P. V. Sastry, K. M. Amm, D. C. Knoll, S. C. Peterson and J. Schwartz, "Synthesis and processing of $(\mathrm{Hg}, \mathrm{Pb})_{1} \mathrm{Ba}_{2} \mathrm{Ca}$ ${ }_{2} \mathrm{Cu}_{3} \mathrm{O}_{y}$ superconductors," Physica C: Superconductivity, vol. 297, no. 3, 223-231, 1998.

DOI: $10.1016 /$ S09214534(97)01861-3

[6] A. K. Pandey, G. D. Verma and O. N. Srivastava, "Investigations on the Tl-doped Hg-Ba-Ca-Cu-O high temperature perconductors in regard to hole doping and microstructural characteristics," Physica C: Superconductivity, vol. 306, no. 1, pp. 47-57, 1998. DOI: 10.1016/S0921-4534(98)00287-1

[7] N. Balchev, F. Van. Allemeersch, F. Persyn, J. Schroeder, R. Deltour and S. Hoste, "The effect of Sn substitution in the superconducting system," Superconductor Science and Technology, vol. 10, no. 1, 65-70, 1997. DOI: 10.1088/0953-

[8] R. Giri, H. K. Singh, R. S. Tiwari and O. N. Srivastava, "Effect of cationic size in $\mathrm{Hg}(\mathrm{Tl} / \mathrm{Bi}) \mathrm{Ba}_{2} \mathrm{Ca}_{2} \mathrm{Cu}_{3} \mathrm{O}_{8+\delta}$ on supercon-

ing and microstructural characteristics," Bulletin of Materials Science, 24, no. 5, pp. 523-528, 2001. D0I: 10.1007/ BF02706725

[9] R. Giri, G. D. Verma, R. S. Tiwari and O. N. Srivastava, "Influence of simultaneous doping Tl and Bi on microstructure and critical current density of $\mathrm{Ba}_{2} \mathrm{Ca}_{2} \mathrm{Cu}_{3} \mathrm{O}_{8+\delta}$," Crystal Research and Technology, vol. 38, no. 9, pp. 760-766, 2003. DOI: $10.1002 /$ crat.200310092

[10] J. H Su, P. V. P. Sastry and J. Schwartz, "Magnetization and transport properties of silver-sheathed (Hg, $\mathrm{Re}) \mathrm{Ba}_{2} \mathrm{Ca}_{2} \mathrm{Cu}_{3} \mathrm{O}_{8+\delta}$ tapes," Superconductor Science and Technology, vol. 16, no. 10, 1134, 2003. DOI: 10.1088/0953-2048/16/10/302

[11] R. Arapaia, M. Ejranis, L. Parlato, F. Ta fure, R. Cristiano, D. Golubev, .... and G. P. Pepe, "High-temperature superconductnanowires for photon detection," Physica C: Superconductivity and its Applications, vol. 509, pp. 16-21, 2015. 
[12] K. A. Jasim, T. J. Alwan, H.K. Al-Lamy, H. L. Mansour, "Improvements of superconducting properties of $\mathrm{Hg} 0.6 \mathrm{Pb0}$. 25Sb0. $15 \mathrm{Ba}_{2} \mathrm{Ca}_{2} \mathrm{Cu}_{3} \mathrm{O}_{8+\delta}$ Ceramic by controlling the sintering time," Journal of Superconductivity and Novel Mag-

netism,

vol. 24, no. 6, pp. 1963-1966. 2011. DOI: 10.1007/s10948-011-1153-1

[13] K. A. Jassim, "The effect of cadmium substitution on the superconducting properties of Tl1- $\mathrm{x} \mathrm{Cd} \mathrm{x} \mathrm{Ba}_{2} \mathrm{Ca}_{2} \mathrm{Cu}_{309-\delta}$ compound," Journal of Superconductivity and Novel Magnetism, vol. 26, no. 3, pp. 549-552, 2013. DOI: 10.1007/s1094 8-012-1787-7

[14] I. Kirschner, R. Laiho, P. Lukács, A. C. Bodi, M. D. Lukács,, E. Lähderanta and G. Zsolt, “Effect of preparation on Hg-Ba-Ca -Cu-O superconductors," Zeitschrift für Physik B Condensed Matter, vol. 99, no. 1, pp. 501-506, 1995. D0I: 10.1007/BF 02769973

[15] K. A. Jasim, "Influence of simultaneous doping of $\mathrm{Tl}$ on the transition temperature Tc and the lattice parameters of $\mathrm{HgBa}_{2} \mathrm{Ca}_{2} \mathrm{Cu}_{3} \mathrm{O}_{8+948}$; Superconductors," Journal of Ibn Al-Haitham for Applied and Pure Science, vol. 22, no. 3, pp. 86-82, 2009.

[16] R. Giri, Singh H. K, R. S. Tiwari and Srivastava, "Effect of cationic size in $\mathrm{Hg}$ (Tl/Bi) $\mathrm{Ba}_{2} \mathrm{Ca}_{2} \mathrm{Cu}_{3} \mathrm{O}_{8+} \delta$ on supercon- ducting and microstructural characteristics," Bulletin of Materials Science, vol. 24, no. 5, pp. 523-528, 2001. DOI:

[17] G. Xing, M. Wang, X. Fan and X. Tang, "The reaction process of the Bi-Sr-Ca-Cu-O system and the forming mechanism of the 2212 superconducting phase," Applied Physics A, vol. 56, no. 2, pp. 99-102, 1993. D0I: 10.1007/BF00517673

[18] K. A. Jasim and T. J. Alwan, "The effect of simultaneous substitution of strontium at the rarium site of $\mathrm{Tl}_{0.6} \mathrm{~Pb}_{0.4} \mathrm{Ba}_{2-\mathrm{x}}$ $\mathrm{Sr}_{x} \mathrm{Ca}_{2} \mathrm{Cu}_{3} \mathrm{O}_{9-\delta}$ superconductors," Journal of Superconductivity and Novel Magnetism, vol. 22, no. 8, pp. 861-865, 2009. DOI: $10.1007 / \mathrm{s} 10948-009-0512-7$

[19] I. F. Ferguson and A. H Rogerson, "A program for the derivation of crystal unit cell parameters from x-ray powder diffraction measurements," Computer Physics Communications, vol. 32, no. 1, pp. 95-107, 1984. DOI: 10.1016/0010-

[20] V. Manivannan, J. Gopalakrishnan and C. N. R. Rao, "Synthesis of cuprates of perovskite structure in the Ba-Pb-CuO, Ba-Bi-Cu-O, and Ba-Pb-Tl-Cu-O Systems: Possible high T c superconductivity in a Perovskite-like phase in the Ba-Pb- $\quad$ Tl-Cu-O System," Journal of Solid State Chemistry, vol. 109, no. 1, pp. 205-209, 1994. DoI: 10.1006/jssc.1994.1093

[21] A. I Abou-Aly, M. F. Mostafa, I. H. Ibrahim, R. Awad and M. A. Al-Hajji, "Electrical and magnetic properties of Hg0. 3Tl0. 7Ba2Ca3Cu4010+ $\delta$ doped with Ni and Ag," Superconductor Science and Technology, vol. 15, no. 6, 938-944, 2002. DOI: $10.1088 / 0953-2048 / 15 / 6 / 318$

[22] H. Eskes and G. A. Sawatzky, "Tendency towards local spin compensation of holes in the high-T c copper compounds," Physical Review Letters, vol. 61, 12, pp. 1415-1418, 1988. DOI: 10.1103/PhysRevLett.61.1415

[23] W. Kingery and H. Brownn, Introduction to Ceramic. New York, NY: Wiley, 1976.

[24] D. Golubev, F. Lombardi and T. Bauch, "Effect of heating on critical current of YBCO nanowires," Physica C: Supercontivity and its Applications, vol. 506, pp. 174-177, 2014. DOI: 10.1016/j.physc.2014.06.013

[25] S. Muthucumaran. S. Pathmarajah and M. I. M. Mowjood. 2015 "Vertical variation of salinity, electrical conductivity, $\quad$ temperature and ph of batticaloa lagoon," International Journal of Applied and Physical Sciences, vol. 1, no. 2, pp.

36- 41. 2015. DOI: $10.20469 /$ ijaps.50003-2

[26] K. Jung-Min and K. Myung-Ho, "The study about indoor temperature effect on productivity by brainwave type of occupants," International Journal of Technology and Engineering Studies, vol. 2, no. 4, pp. 117-124, 2016.

DOI: $10.20469 /$ ijtes.2.40004-4

— This article does not have any appendix. — 